Relations industrielles

Industrial Relations

\title{
La nouvelle loi fédérale des relations du travail
}

\section{Denys Dion}

Volume 4, numéro 3, novembre 1948

URI : https://id.erudit.org/iderudit/1023446ar

DOI : https://doi.org/10.7202/1023446ar

Aller au sommaire du numéro

Éditeur(s)

Département des relations industrielles de l'Université Laval

ISSN

0034-379X (imprimé)

1703-8138 (numérique)

Découvrir la revue

Citer cet article

Dion, D. (1948). La nouvelle loi fédérale des relations du travail. Relations

industrielles / Industrial Relations, 4(3), 30-30. https://doi.org/10.7202/1023446ar

Tous droits réservés @ C Département des relations industrielles de l’Université Laval, 1948
Ce document est protégé par la loi sur le droit d'auteur. L'utilisation des services d'Érudit (y compris la reproduction) est assujettie à sa politique d'utilisation que vous pouvez consulter en ligne.

https://apropos.erudit.org/fr/usagers/politique-dutilisation/ 


\section{LA NOUVELLE LOI FÉdÉRALE DES RELATIONS DU TRAVAIL ET LE C. P. 1003}

\section{Denys Dion}

Le C. P. 1003 du 17 février 1944 concernant les « Règlements des Relations ouvrières en temps de guerre », suspendait la «Loi des Enquêtes en matière de différends industriels» connue plus communément sous le nom de Loi Lemieux. Or la présente loi est destinée à remplacer l'une et l'autre définitivement. Elle a été déposée à la Chambre le 17 juin 1947, par ie Ministre fédéral du Travail soús le titre de «Loi sur les relations industrielles et sur les enquêtes visant les différends du travail. » Après une longue et sérieuse étude par le Comité permanent des Relations industrielles et par les deux Chambres elle vient d'être votée en troisième lecture le 17 juin 1948.

Mais que peut nous apporter de nouveau cette loi? Bien des choses dont nous voulons souligner ici les plus importantes. On peut dire d'abord que contrairement au C. P. 1003 qui n'était qu'un règlement du Conseil Privé destiné à faire face à la période difficile des temps de guerre, la nouvelle réglementation est une loi du Parlement. C'est dire qu'elle a passé par le feu des deux Chambres en plus d'avoir subi l'épreuve du Comité des Relations ouvrières, avant d'être signée par le Gouverneur en conseil.

Dans la loi elle-même, il faut d'abord noter l'interprétation du mot «travailleur » qui subit une modification. Le C. P. 1003, en effet, ne considérait pas comme travailleur «toute personne employée à titre confidentiel ou ayant compétence pour embaucher ou congédier des travailleurs ». Tandis que maintenant on ne considère pas comme travailleur au sens de la présente loi « un gérant ou surintendant, ni une autre personne qui, de l'avis du Conseil, exerce des fonctions de direction ou est employée à titre confidentiel dans des matières concernant les relations ouvrières. » On voit de prime abord que dans la première partie de l'exception, on donne une extension assez grande au mot travailleur alors qu'on en restreint le sens dans la seconde. Il y a une seconde exception que la nouvelle loi énonce au sujet du mot travaileur, où elle exclut nommément certaines professions comme le droit, la médecine, le génic, etc., qui ont des statuts provinciaux spéciaux.
Mais une des principales différences existe, croyons-nous, au sujet de l'accréditation. En effet, alors que dans le C. P. 1003, c'était les représentants des syndicats pris individuellement qui étaient choisis comme agents négotiateurs; selon la nouvelle loi, l'accréditation ne sera donnée qu'au seul syndicat. De plus, il faut maintenant que le syndicat qui veut être accrédité compte comme membres en règle, la majorité des ouvriers qu'il veut représenter alors qu'avant on se contentait d'autorisations écrites par les travailleur en faveur du syndicat. En plus, le Conseil, avant d'accorder l'accréditation, a le pouvoir de juger si un syndicat ouvrier est influeneé ou dominé de quelque manière que ce soit par l'employeur. Le Conseil peut alors refuser l'accréditation et toute convention collective signée par un tel syndicat est de nul effet au point de vue de la nouvelle loi. La présente loi donne aussi au Conseil le pouvoir de révoquer l'accréditation d'un syndicat, s'il le juge à propos. L'ancienne loi se contentait de prévoir, suivant certaines conditions, le remplacement des agents négotiateurs.

On défend maintenant de tenir un scrutin de grève chez les travailleurs avant d'avoir épuisé tout le processus de conciliation.

Pendant tout le cours des négociations de la conciliation, le patron ne peut, sans le consentement de ses employés, changer les taux de salaire ou les conditions de travail.

Enfin, une disposition nouvelle très importante stipule que dans les poursuites pour infraction tombant sous l'empire de la présente loi, une organisation patronale ou un syndicat ouvrier sont considérés comme des personnes morales.

Voilà, à notre sens, les plus importantes différences qui existent entre les deux lois. Comme on le voit, ces changements dans notre législation fédérale sont très caractéristiques et marquent l'évolution profonde qui s'est accomplie à date et continue de s'accomplir dans le domaine si vaste et brûlant des relations industrielles. 